\title{
La cooperación de China en América Latina: ¿hacia una Nueva Economía Estructural?
}

\author{
A Cooperação da China na América Latina: \\ Rumo a uma Nova Economia Estrutural?
}

\author{
Chinese cooperation in Latin America: \\ itoward a New Structural Economics?
}

DOI: $10.21530 /$ ci.v13n2.2018.806

Eduardo Crivelli Minutti ${ }^{1}$
Giuseppe Lo Brutto ${ }^{2}$

\section{Resumen}

Durante la primera década del siglo XXI, América Latina fortaleció sus relaciones con China, hasta convertirse en un socio estratégico para el comercio, la inversión y la cooperación de este país asiático. Se trata de una asociación estratégica que, comprendida bajo la teoría de la Nueva Economía Estructural, se aleja de los esquemas tradicionales de ayuda para revestir a la cooperación al desarrollo de dialogo político, acuerdos comerciales, inversiones y préstamos no-concesionados en infraestructura, buscando reequilibrar las relaciones económicas internacionales. Por tal motivo, el objetivo de este trabajo es dar cuenta de la cooperación al desarrollo que China realiza en los marcos de una posible transformación estructural en la región latinoamericana.

Palabras clave: Cooperación Sur-Sur; Nueva Economía Estructural; China; América Latina.

1 Maestro en Sociología por el Instituto de Ciencias Sociales y Humanidades "Alfonso Vélez Pliego" (ICSyH) de la Benemérita Universidad Autónoma de Puebla (BUAP). Estudiante del Doctorado en Sociología en el ICSyH-BUAP. Profesor de la Licenciatura en Relaciones Internacionales de la Facultad de Derecho y Ciencias Sociales de la BUAP. Secretario del Grupo de Investigación en Cooperación Sur-Sur e Integraciones Regionales (GI CSS-IR) de la Red Española de Estudios del Desarrollo (REEDES). edoardocrivelli@hotmail.com

2 Doctor en Economía Política del Desarrollo por la de la Benemérita Universidad Autónoma de Puebla (BUAP). Profesor-investigador titular del Posgrado en Sociología del Instituto de Ciencias Sociales y Humanidades "Alfonso Vélez Pliego" (ICSyH) de la BUAP. Coordinador del Grupo de Investigación en Cooperación Sur-Sur e Integraciones Regionales (GI CSS-IR) de la Red Española de Estudios del Desarrollo (REEDES). Miembro del Sistema Nacional de Investigadores (SNI) del Consejo Nacional de Ciencia y Tecnología (CONACyT) de México. Correo: giuseloby@msn.com

Artigo submetido em 21/05/2018 e aprovado em 16/08/2018. 


\title{
Resumo
}

Durante a primeira década do século XXI, a América Latina fortaleceu as suas relações com a China até se tornar um sócio estratégico para o comércio, o investimento e a cooperação com o país asiático. Trata-se de uma associação estratégica que, compreendida sob a teoria da Nova Economia Estrutural, se afasta dos esquemas tradicionais de ajuda que norteiam a cooperação para o desenvolvimento de diálogo político, acordos comerciais, investimentos e empréstimos não-concessionados em infraestrutura, buscando reequilibrar as relações econômicas internacionais. Deste modo, o objetivo do trabalho é analisar a cooperação para o desenvolvimento que a China realiza nos marcos de uma possível transformação estrutural na região latino-americano.

Palavras-chave: Cooperação Sul-Sul; Nova Economia Estrutural; China; América Latina.

\begin{abstract}
During the first decade of the 21st century, Latin America strengthened its relations with China until becoming a strategic partner for the trade, investment and cooperation of this Asian country. It is a strategic association that, under the theory of the New Structural Economy, moves away from the traditional aid schemes to revert to the development cooperation of political dialogue, trade agreements, investments and non-concessional loans in infrastructure, seeking to rebalance the international economic relations. For this reason, the objective of this work is to give an account of the development cooperation that China is making in the framework of a possible structural transformation in the Latin American region.
\end{abstract}

Key words: South-South Cooperation; New Structural Economics; China; Latin America.

\section{Introducción}

Al volver a examinar las estrategias para lograr un desarrollo sostenible en los países del Sur ante la reciente crisis financiera, Justin Yifu Lin (2010; 2012), en colaboración con Ya Wang (LIN; WANG; 2017), ha propuesto la teoría de la Nueva Economía Estructural (NEE), en un afán de valorizar el cambio estructural y la modernización industrial que no han recibido la suficiente atención en la literatura económica tradicional, resultando insuficiente a la hora de buscar estrategias efectivas para impulsar un crecimiento sostenible (LIN, 2010, p. ii). 
Haciendo uso del enfoque neoclásico, la NEE basa su hipótesis en el hecho de que la estructura económica (incluida la tecnología, la industria y la infraestructura dura y blanda ${ }^{3}$ ) es endógena a la estructura de dotación factorial, que se da en cualquier momento específico y que cambia en el tiempo. Por ello, seguir la ventaja comparativa para desarrollar industrias es la mejor manera para que un país sea competitivo, tenga excedentes económicos, fomente el ahorro y mejore la estructura de dotación, manteniendo la modernización industrial, crecimiento en ingresos y reducción de la pobreza. Esto se da/ocurre con la necesidad de generar un mercado competitivo para las industrias en desarrollo de acuerdo con las ventajas comparativas de cada país y un Estado desarrollista facilitador de mejorar su "infraestructura dura y blanda que la modernización industrial requiere" (LIN; WANG, 2017, p. 15-16 ). En otras palabras, la NEE sustenta una estrategia de desarrollo acompañada de recomendaciones de política económica.

Ante ello, la hipótesis que guía este trabajo es que la NEE surge como una teoría-estrategia política que puede reconfigurar e incluso ser la base para la construcción de un nuevo régimen de cooperación al desarrollo bajo el liderazgo de Beijing ${ }^{4}$. A la luz de esta premisa, como hipótesis predictiva, la cooperación entre China y América Latina (AL) se insertará en el esquema de la Nueva Ruta de la Seda propuesta por el presidente Xi Jinping, aunque este macroproyecto ha desplazado por ahora solo algunas sinergias hasta dicha región.

En este panorama, el objetivo del presente artículo es identificar algunas cuestiones sobre los procesos de cooperación entre China y AL en su avance hacia un nuevo régimen de cooperación internacional, comprendido bajo la teoría de la NEE. Para lograr dicho cometido y deslumbrar aquellos elementos que permiten avanzar hacia nuestra hipótesis de trabajo, este artículo se divide en cuatro partes,

3 La infraestructura "dura” (hard) se refiere a aquello tangible, como las carreteras, puentes, puertos, etc.; mientras que la "blanda" o "suave" (soft) se relaciona con aquello intangible, como el ambiente financiero y legal para la implementación de las inversiones. Ambos tipos de infraestructura son necesarios para facilitar las transacciones de producción y de mercado, permitiendo que la economía llegue a su frontera de posibilidades de producción al reducir los costos de transacción (LIN; WANG, 2017, p. 25).

4 Recuperando la tradición desarrollista de las teorías dependentistas a favor de una transformación de la estructura productiva (industrialización), los países del G77 y China afirmaron un compromiso para dar forma a la agenda internacional para el desarrollo después de 2015, en cuyo centro está la teoría de la NEE (DOMÍNGUEZ, 2017, p. 70). La NEE es considerada la teoría económica que sustenta el nuevo régimen internacional de CSS, asumiendo el patrón difusionista del desarrollo a partir de la trayectoria en V invertida (flying geese pattern), según la cual China, en su proceso de graduación en desarrollo, reasignará las industrias más intensivas en mano de obra hacia otros países menos desarrollados, donde la inversión en infraestructuras permitirá capturar esa ventana de oportunidad por las ventajas de una mano de obra más barata, generando empleos, reduciendo la pobreza y ayudando así a subir por la escalera del desarrollo como hizo China en su historia reciente (DOMÍNGUEZ, 2018, p. 61). 
partiendo, en primer lugar, de algunas consideraciones generales sobre las nuevas dinámicas de la cooperación internacional que permitan diferenciarlas de la ayuda tradicional; en segundo lugar, se reflexiona sobre la intensificación de las relaciones entre China y AL en el siglo XXI, poniendo énfasis en el hecho de que el sistema de ayuda chino se articula en el diálogo político, acuerdos comerciales y una nueva forma de financiación del desarrollo ${ }^{5}$; en tercer lugar se presentan una serie de datos que permiten considerar si China y los países latinoamericanos van avanzando hacia la NEE; y, por último, se presentan algunas consideraciones finales que permiten ayudarnos a vislumbrar los procesos de cooperación china en la región.

\section{Las nuevas dinámicas de la cooperación internacional}

Durante la segunda mitad del siglo XX, la ideología de la cooperación internacional para el desarrollo (CID) justificó un conjunto de medidas económicas y políticas con el propósito teórico de promover el progreso económico y social en aquellas "zonas atrasadas", que supuestamente debían transitar al desarrollo (LO BRUTTO, 2017, p. 59). Aunque lejos de ser un concepto aplicable a todo tiempo y lugar, la CID tuvo diferentes enfoques, prioridades y modalidades operativas, resultando en la mayoría de los casos un recurso a favor del posicionamiento político y geoestratégico que promocionó los intereses empresariales privados de los países ricos en detrimento del interés público de los países receptores más pobres ${ }^{6}$.

Sin embargo, desde finales del siglo pasado, las cosas empezaron a cambiar y la mayoría de los países de renta media alta iniciaron a consolidar su posición internacional como receptores y donantes de cooperación, aunque casi exclusivamente bajo las modalidades de la asistencia técnica e intercambios de

5 Rafael Domínguez (2016, p. 68-69) señala que la Cooperación Sur-Sur (CSS) hizo desde sus inicios un uso intensivo de los tres pilares que incluye la Cooperación Internacional para el Desarrollo (CID) como herramienta de política exterior: el diálogo político; los acuerdos comerciales y la cooperación financiera y técnica. Es por ello que nuestra hipótesis de trabajo se sustenta en el hecho de que hoy la cooperación china recupera el sentido de lo que fue la CSS en los '50 del siglo pasado, intentando analizar el fenómeno en cuestión con una perspectiva histórica y crítica.

6 La ayuda tradicional al desarrollo ha resultado en gran medida inadecuada para impulsar el crecimiento en las economías de mercado emergentes, por ello, alcanzar los Objetivos del Desarrollo Sostenible (ODS) para el 2030, así como combatir el cambio climático según los objetivos en la última reunión del COP21, requerirá grandes cantidades de recursos que parecen inalcanzables (LIN; WANG, 2017, p. 1). 
buenas prácticas. La creciente importancia de la cooperación Sur-Sur (CSS) ${ }^{7}$ y de la cooperación triangular permitieron ganar mucho terreno en el reconocimiento de las capacidades de estos países menos desarrollados para complementar los flujos tradicionales de cooperación y contribuir a la provisión de bienes públicos globales (DOMÍNGUEZ; RODRÍGUEZ, 2017, p. 8).

La secuencia histórica de la CID se vio modificada, porque el mundo en desarrollo se hizo cada vez más diverso y complejo, así como por el desplazamiento parcial de los centros de gravitación del poder económico y político a escala internacional, sobre todo debido al surgimiento de nuevas potencias regionales y globales que han pasado de ser receptores a proveedores de cooperación. La emergencia de nuevos actores también generó un doble desafío en la agenda de investigación, pues obligó a indagar sobre el grado de correspondencia que existe entre la realidad de su proceder internacional y los atributos que los propios países otorgan a su cooperación; asimismo se develó la necesidad de trascender los rasgos que se consideran comunes para investigar las diferencias de los modelos de CSS (SANTANDER, 2016, p. 18-19).

El cambio en las dinámicas de la CID se observa en el paso del bilateralismo al multilateralismo en un escenario en el que China ha sabido tomar un gran liderazgo, formando cuerpos multilaterales que reflejan sus ideas de desarrollo, experiencias y conocimiento táctico para una inclusiva y sustentable transformación estructural del Sur global, incluyendo a muchos países latinoamericanos que participan activamente en este proceso (LIN; WANG, 2017 p. 7).

En este sentido, se recupera la idea de la "crisis de identidad" de la tradicional forma de cooperación internacional para el desarrollo como resultado de las contradicciones recurrentes del sistema de ayuda, la proliferación de nuevos actores públicos y privados, así como por la disolución de la metáfora jerárquica Norte-Sur ordenadora de las relaciones internacionales (DOMÍNGUEZ, 2011, p. 1). Así, surge una nueva identidad de la CSS como la continuidad a la crisis de identidad de la tradicional forma de cooperación Norte-Sur (LO BRUTTO; GONZÁLEZ, 2015, p. 11). Por eso, es importante comprender la geopolítica internacional contemporánea en la que China y otras potencias emergentes pueden desempeñar un papel

7 La CSS nace de la confluencia del Movimiento de Países No Alineados (1961) tras la conferencia de Bandung (1955) y la creación el G77 (1964) en el seno de la UNCTAD (Conferencia sobre Comercio y Desarrollo), a la que luego se invitaría a China, que había asistido a Bandung como asociado permanente cuando tomó su asiento en Naciones Unidas, en 1971. En ese sentido, la CSS fue un intento de construir coaliciones internacionales para cambiar el orden económico mundial (DOMÍNGUEZ, 2016, p. 67). 
benigno hacia un orden mundial más razonable y estable, a través de una cabal comprensión de la propia CSS en perspectiva histórica (DOMÍNGUEZ, 2017, p. 61).

De esta forma, a partir del proyecto de expansión global de China en el siglo XXI, la NEE busca ser una estrategia efectiva y sustentable para que un país de bajos ingresos alcance un crecimiento y un desarrollo dinámico al fortalecer aquellos sectores en los que tiene ventajas comparativas latentes, es decir, en donde los costos de producción son bajos, pero los costos transaccionales son altos debido a una infraestructura dura y blanda inadecuadas (LIN, 2012, p. 6).

Siguiendo a Rafael Domínguez (2016), se observa que el discurso de la CSS, como relación horizontal, encuentra su coherencia con el mandato de las agencias, secretarías o direcciones de cooperación internacional centradas en la cooperación no reembolsable. No obstante, los valores de horizontalidad, respeto de la soberanía, no condicionalidad y beneficio mutuo vinculados a buena parte de la retórica y autolegitimación de la CSS también se han transmitido a los donantes del Comité de Ayuda al Desarrollo (CAD), pero con un doble efecto perverso, al entorpecer el entendimiento cabal de la misma y obstaculizar el fortalecimiento de la CSS para el desarrollo como proyecto de régimen internacional.

Al defender la idea de la financiación del desarrollo como alternativa a la Ayuda Oficial al Desarrollo (AOD), China define su postura de ir más allá de la ayuda hacia una estrategia más amplia, incluyendo el comercio y la inversión que podrían llevar a la transformación estructural de AL. Por eso, en la era de la NEE se revisa la definición de AOD que propone la Organización para la Cooperación y el Desarrollo Económicos (OCDE) ${ }^{8}$, que ni siquiera incluye los instrumentos básicos para facilitar la transformación estructural en los países receptores, como lo son la inversión de capital y los grandes préstamos no-concesionales para infraestructura9 .

8 La AOD es definida como aquellos flujos dirigidos a países y/o a instituciones multilaterales de desarrollo que figuran en la lista de países receptores del CAD y que son proporcionados por organismos oficiales, incluidos gobiernos estatales y locales, cuyas transacciones se administran con el objetivo de promover el desarrollo y el bienestar económicos de los países en desarrollo y son de carácter concesional, llevando un elemento de donación de al menos el $25 \%$ (OECD, 2008, p. 1). Sin embargo, esta categorización ha generado orientaciones concretas que han impulsado y a la vez reprimido y negado ciertas prácticas sociales llamadas CID en desmedro de otras (LEMUS, 2017, p. 44).

9 China ha dejado en claro que la inversión y el comercio son el eje sobre el cual se debe mover la cooperación para el desarrollo, los cuales han comprobado ser herramientas más efectivas para la reducción de la pobreza y la disminución de la igualdad. Esto ha sido acompañado por la ideología China de la ayuda mutua en relación con su experiencia de crecimiento a los países con los que coopera, ofreciéndoles la metodología en las cuales ellos se han especializado (LIN; WANG, 2017, p. 7). 
Ante ello, como se verá en el siguiente apartado, China ha sabido combinar la ayuda con comercio e inversión para que tanto los donantes como los receptores se beneficien por igual, evitando los famosos “cuellos de botella” característicos del modelo de AOD estándar, que separa la ayuda del comercio y la inversión privada y que, en consecuencia, impide que los países exploten sus ventajas comparativas (LIN; WANG, 2017, p. 2-3). Pero para llegar a este punto ha sido fundamental el dialogo político y la formalización de distintos acuerdos comerciales que van en línea con los planes chinos de expansión global, en los que AL juega un papel muy importante.

\section{La intensificación de las relaciones entre China y América Latina}

Con el fin de dejar atrás antiguos enfoques de economía estructural basados en sustitución de importaciones que afectan negativamente a la competitividad de varias cadenas de valor, prohibiendo las importaciones y aumentando los aranceles, la NEE opta, más bien, por reformular las políticas comerciales con la gradual liberalización del comercio, pero en cuya transición el Estado considere proporcionar cierta protección temporal a las industrias que no son consistentes con la ventaja comparativa del país (LIN, 2012, p. 242). En la reformulación de políticas comerciales, el diálogo y los acuerdos son fundamentales a la hora de reforzar los posicionamientos políticos comunes y lograr una inserción autónoma, no dependiente, en la globalización.

Por eso, si bien las relaciones de China con AL no son nuevas, si lo es su intensificación en los últimos años. Sobre todo en el marco de la Guerra Fría (1947-1991), la estrecha relación geopolítica con los Estados Unidos (EEUU) impidió que la política de ayuda exterior de la República Popular China (RPCh) fuera prominente en esta región. Sin embargo, la historia de la relación ChinaAL muestra que la ayuda china ha sido una palanca diplomática indispensable para promover el establecimiento y consolidación de relaciones diplomáticas y comerciales entre ambas partes. En lo que va del siglo XXI, 20 países de AL han recibido diferentes formas de ayuda de China, siendo los países del Caribe los principales receptores (HONGBO, 2017, p. 281).

Desde la primera gira oficial del presidente Jiang Zemin, en 2001, y después con las visitas del presidente Hu Jintao, en 2004, 2005 y 2008, China operó siguiendo el principio de no provocación a los EEUU, pero ocupando paulatinamente espacios dejados por los estadounidenses (DOMINGUEZ, 2017, p. 69). La RPCh empezó 
a esbozar otra forma de ayuda y cooperación al desarrollo que ha mejorado su imagen y erosionado indirectamente el poder estadounidense en AL, a partir de una política comercial que marcó su inició con la firma de un Tratado de Libre Comercio (TLC) con Chile, en el 2006. El gobierno chino se mostró interesado en fortalecer sus relaciones con los países latinoamericanos, publicando, incluso, en 2008, un documento conocido como "El libro Blanco de las Políticas de China hacia América Latina”, en el que por primera vez las autoridades chinas enunciaron que sus vínculos con la región deberían basarse en relaciones de equidad y cooperación mutuamente beneficiosas (MRERPC, 2016). Posteriormente, en el 2010, Perú también subscribió un TLC con China y un año después lo hizo Costa Rica, abriendo, de esta forma, la puerta y las condiciones arancelarias para el acceso al mercado chino considerablemente más favorables que el régimen general de nación más favorecida en el que se habían basado las transacciones precedentes (MARTÍNEZ, 2015).

Los países latinoamericanos vieron con buenos ojos la invitación para integrarse a los proyectos chinos en el ámbito del comercio, las inversiones y el desarrollo infraestructural y, en este contexto, el gobierno chino reafirmó su compromiso con AL a través de la implementación del Plan de Cooperación " $1+3+6$ " 10 , anunciado por el presidente Xi en la IV Cumbre de los BRICS, en 2014, en donde, además, se invitó a la Comunidad de Estados Latinoamericanos y Caribeños (CELAC) a sumarse a esta iniciativa. Así, en 2015, en el marco de la Primera Cumbre CELAC-China, se confirmó para esta región un crédito chino especial en infraestructura por un monto de USD 20.000 millones; líneas de crédito preferencial de USD 10.000 millones y un fondo de USD 5,000 millones, así como también otro fondo especial de cooperación agrícola de USD 50 millones más. Para el afianzamiento de los distintos proyectos de cooperación enmarcados en ese plan, también se contemplaron 6.000 becas de capacitación para los países miembros de la CELAC y un programa de invitación de 1.000 líderes de partidos políticos a China y la formación de otros 1.000 líderes en la región en los sucesivos cinco años (PORTELLES, 2015).

Es evidente que China también se ha preocupado por promover un intercambio cultural más estrecho con los países latinoamericanos al fortalecer su presencia en los órganos legislativos, partidos políticos y gobiernos locales, es decir, con

10 La fórmula “ $1+3+6$ ” parte de un programa de cooperación de los próximos cinco años (2015-2020) que pretende avanzar con la fuerza de tres motores: el comercio, la inversión y la cooperación financiera, con los que se desarrollan seis ejes en el ámbito de la cooperación energética, recursos naturales, construcción de infraestructuras, agricultura, manufactura, innovación tecnológica y tecnología informática (PORTELLES, 2015). 
todos aquellos actores importantes en la toma de decisiones y, en consecuencia, de fundamental importancia para el desarrollo de la diplomacia china en esta región.

AL es importante para la diplomacia del gobierno de Beijín que busca ganar aliados en la resolución de la controversia sobre el estatus político y el reconocimiento internacional de Taiwán como parte de la RPCh. De los 18 países que reconocen a Taiwán como Estado soberano, 10 se encuentran en AL, motivo por el cual el gobierno chino pide a los países de esta región que mantengan su política de reconocimiento de "una sola China" - como consecuencia, por ejemplo, en 2007 Costa Rica optó por romper la relación de más de 60 años con la isla para establecer relaciones con la RPCh (BBC, 2017).

La diplomacia china se ha intensificado desde que Xi Jinping visitó AL como vicepresidente, en 2009 y 2011, y luego como presidente, en 2013, 2014 y 2016, lo que ya suma cinco visitas a la región, firmando más de 280 acuerdos con 11 países ${ }^{11}$, cifra que podría elevarse si se consideran las visitas de otros dignatarios chinos a AL y las numerosas visitas de los presidentes y dignatarios latinoamericanos en China (IISCAL, 2016).

De esta forma, China ha ido ganando terreno en AL, consolidándose hoy como el principal socio comercial de Brasil, Chile y Perú y el segundo en importancia para México, Argentina y Venezuela. Pero a diferencia de los EEUU y otras potencias europeas, este país asiático se ha insertado en la región como un actor pragmático, mostrando mayor interés en las relaciones económicas y comerciales que en los aspectos políticos internos.

El compromiso estratégico con la región fue refrendado una vez más en 2016, con un segundo “Documento sobre la Política China hacia América Latina”, complementando el texto lanzado ocho años antes debido a la creciente inversión de las empresas chinas que se alinearán con las necesidades de los países latinoamericanos para un desarrollo independiente (MRERPC, 2016), y luego a finales de 2017, cuando el gobierno chino propuso un TLC entre su país y la CELAC. Por estos motivos, muchos gobiernos de AL han descartado la preocupación sobre la posible injerencia de la RPCh en los asuntos políticos locales, vislumbrando en la política comercial china una ventana de oportunidad para el desarrollo estructural de la región.

11 En el marco de la visita del Presidente Xi Jinping a México, Costa Rica, y Trinidad y Tobago, en junio de 2013, se firmaron más de 25 acuerdos. Luego, durante su visita a Brasil, Venezuela, Argentina y Cuba, en julio de 2014, se consolidaron más de 120 acuerdos. Más de 70 acuerdos fueron firmados, también, durante la visita del Premier Li Keqiang en Brasil, Colombia, Perú y Chile, en mayo de 2015, y posteriormente fueron concretados más de 30 tras su estancia en Cuba, en septiembre de 2016. Recientemente, en noviembre de 2016, se firmaron 41 acuerdos durante la nueva visita de Xi Jinping a Ecuador, Perú y Chile (IISCAL, 2016). 


\section{China y América Latina ¿hacia una Nueva Economía Estructural?}

A diferencia de otros donantes tradicionales, China se ha caracterizado por disponer de asistencia rápida y eficaz, con cooperación pragmática y selectividad bilateral que atiende a las necesidades de AL por diversificar sus relaciones políticas y comerciales, avanzando en una agenda de dialogo que facilita el comercio, las inversiones y la colaboración (CEPAL, 2011, p. 30-32). Así bien, la NEE sugiere la liberación gradual del comercio en un enfoque pragmático de doble vía que ayude a una economía en transición a evitar interrupciones socioeconómicas innecesarias y costosas, mientras la conduce a un sistema de precios basados en el mercado y asignación de recursos (LIN, 2012, p. 78).

En esta lógica, el comercio entre AL y China se ha intensificado en los últimos años, siendo mutuamente beneficioso, en la medida en que los países latinoamericanos empezaron a diversificar sus destinos de exportación y los chinos accedieron a una fuente confiable de recursos para potencializar su desarrollo. Por ello, el comercio bilateral entre ambas partes pasó de USD 15.765 millones en el año 2001, llegando a un máximo de USD 277.175 millones en el 2014, con un crecimiento promedio del $26 \%$ anual $^{12}$, tal y como se muestra en la siguiente gráfica.

\section{Grafica 1. Comercio de bienes entre América Latina y China (2000-2017)}

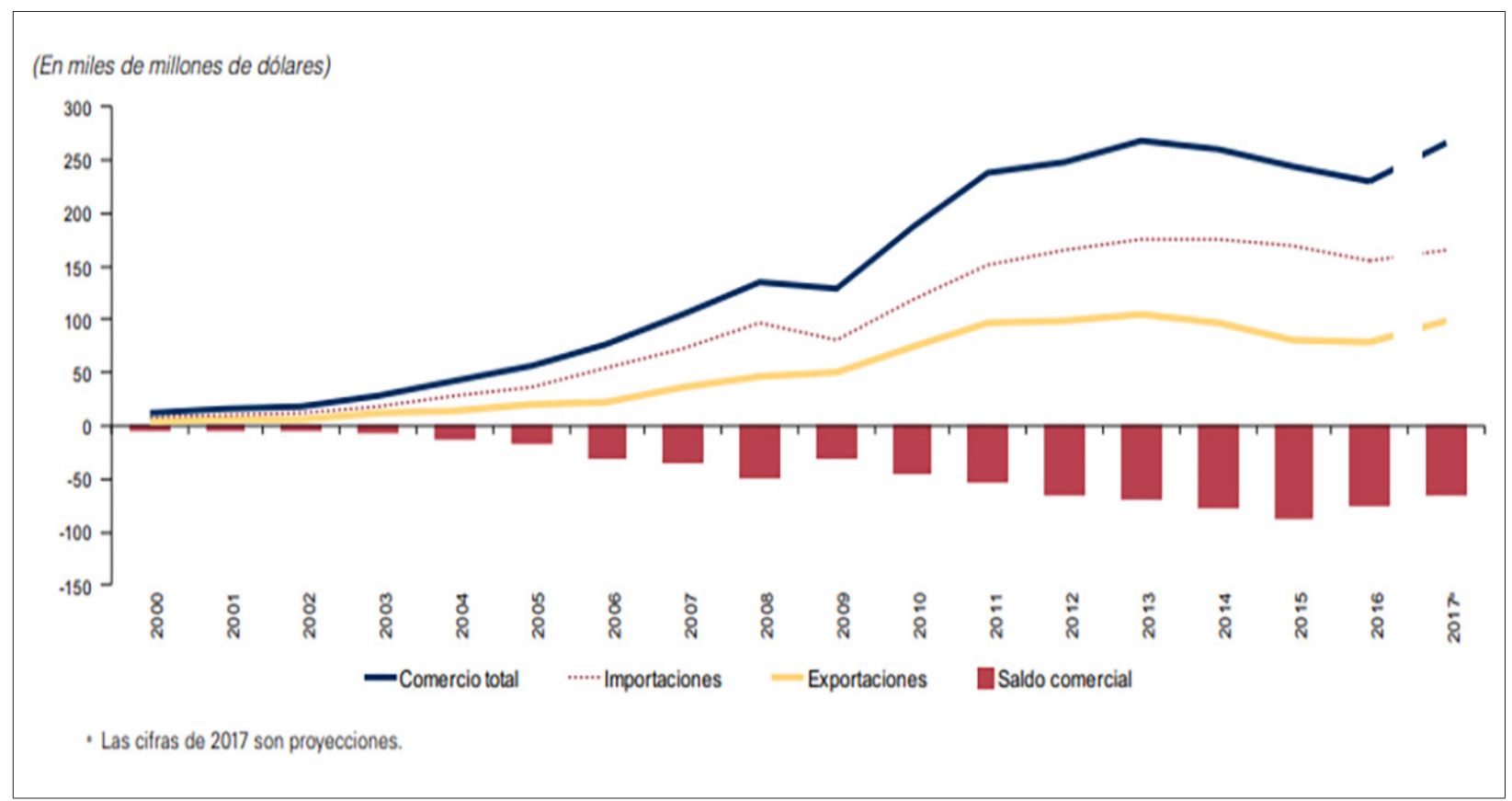

Fuente: CEPAL, (2018, p. 39 ).

12 Se trata de una cifra considerable si se tiene en cuenta que el comercio de AL con el mundo creció a razón del $10 \%$ durante el mismo período (ROLDÁN, et alt.2016, p. 37). 
Los economistas suelen coincidir en que el mercado debe ser el mecanismo básico para la asignación de recursos, pero es el gobierno quien debe desempeñar un papel activo en la coordinación de inversiones para la modernización y diversificación industrial y en la compensación de externalidades generadas por los primeros motores en el proceso dinámico de crecimiento. Por eso, en un nuevo enfoque de economía estructural, los países que cooperan dan cuenta de las lecciones aprendidas de los éxitos y fracasos del crecimiento de las últimas décadas, avanzando en un enfoque neoclásico para estudiar los determinantes y la dinámica de la estructura económica de cada parte involucrada (LIN, 2012, p. 6) .

Desde esta perspectiva, se comprende que, al especializarse en la producción y exportación de materias primarias, cuyos costes de producción son relativamente más bajos respecto al resto del mundo y por tanto en ventaja comparativa, desde el año 2001, el 51 \% de las exportaciones de AL hacia la RPCh se centraran principalmente en productos básicos, cifra que ascendió al 71\% en 2014, mientras que las exportaciones de bienes intermedios representaron el 24\%, los bienes de consumo el $3 \%$ y otros bienes el $2 \%$, pese a tener mayor valor agregado (ROLDÁN et al, 2016, p. 37). En la siguiente tabla se muestran las cinco principales mercancías latinoamericanas exportadas hacia China y las importaciones desde este país en AL desde 2011 hasta 2015.

Tabla 1: 5 Principales importaciones y exportaciones, 2011-2015

\begin{tabular}{lclc}
\hline \multicolumn{1}{c}{$\begin{array}{c}\text { Exportaciones de ALyC } \\
\text { hacia China }\end{array}$} & Porcentaje & \multicolumn{1}{c}{$\begin{array}{c}\text { Importaciones de ALyC } \\
\text { procedentes de China }\end{array}$} & Porcentaje \\
\hline Soja, Otras Semillas Oleaginosas & $19.2 \%$ & Equipos de telecomunicaciones & $9.7 \%$ \\
Menas, Concentrados de Hierro & $16.8 \%$ & Máquinas de procesamiento de datos & $3.8 \%$ \\
Cobre & $12.2 \%$ & Barcos, botes y estructuras flotantes & $3.3 . \%$ \\
Petróleo no refinado & $11.8 \%$ & Instrumentos y aparatos ópticos & $3.3 \%$ \\
Menas, concentrados de Cobre & $10 \%$ & Otros equipos eléctricos & $2.3 \%$ \\
\hline Total de las 5 principales & $\mathbf{6 9 . 2 \%}$ & Total de las 5 principales & $\mathbf{2 2 . 5 \%}$ \\
exportaciones respecto al resto & & importaciones respecto al resto & \\
\hline
\end{tabular}

UNSD, 2017.

Analizados estos datos desde la tradicional perspectiva del CAD, que separa la ayuda del comercio, la preocupación de muchos especialistas gira en torno a pensar que, al asignar a los países latinoamericanos un rol de subordinación en la producción de materias primas, China se ha ido consolidando como un exportador 
de productos manufacturados que tienen mayor valor agregado, generando cierta dependencia económica de los países de la región, que, por el contrario, han tenido relativamente poco éxito en la comercialización de sus manufacturas en este país asiático ${ }^{13}$. Por lo tanto, los países latinoamericanos se verían afectados por los cambios de la economía china ${ }^{14}$, tal y como se muestra en el siguiente mapa en el que se observa la exposición de los países de AL ante los cambios en la demanda China, a partir de un índice de dependencia de las exportaciones aplicado y medido de 0 a 1 , indicando entre más alto sea el número, más expuesto está el exportador a disrupciones en el comercio con China ${ }^{15}$.

\section{Mapa 1: Dependencia de los países latinoamericanos hacia China}

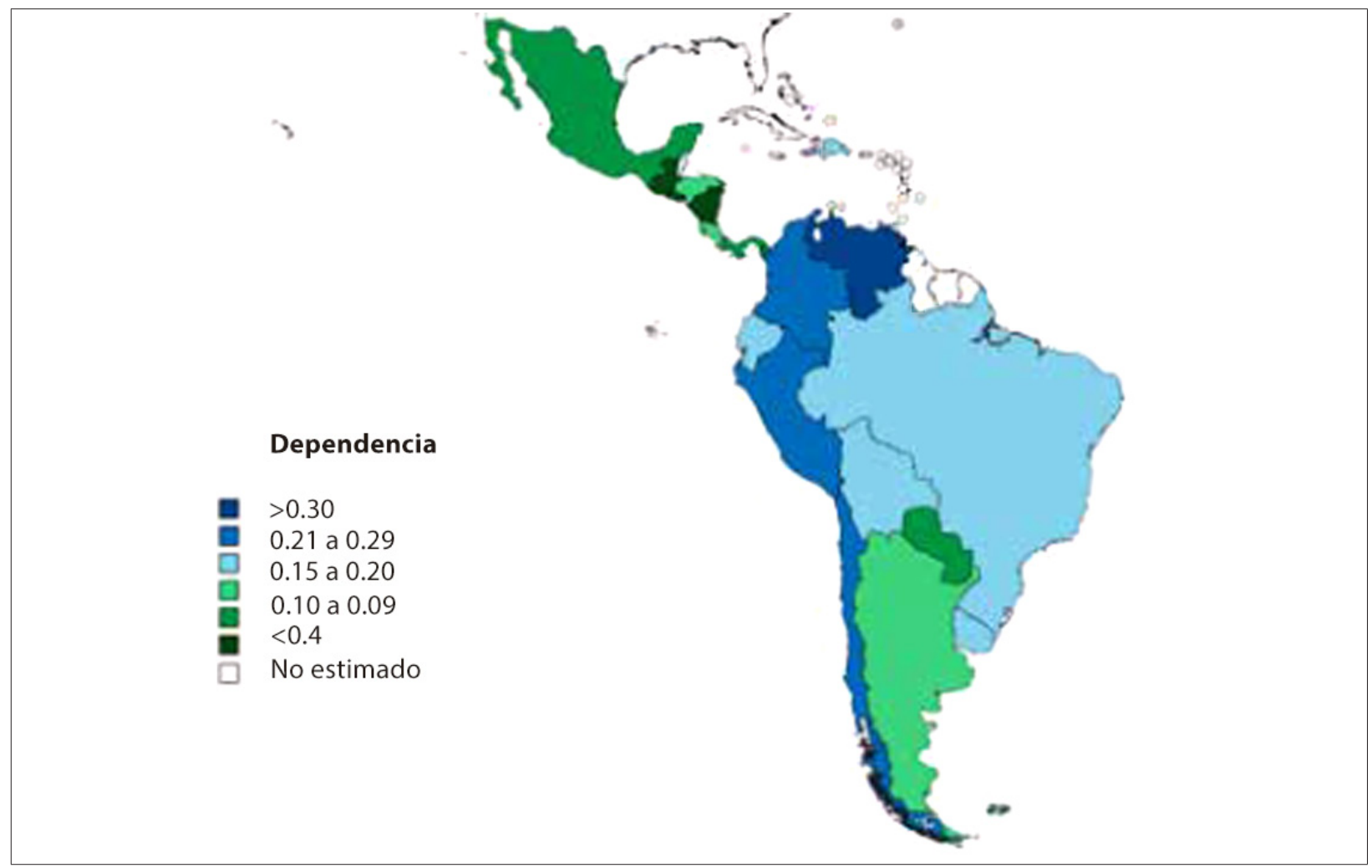

Fuente: ROLDÁN, et al, 2016, p. 39

13 Estas consideraciones fueron desarrolladas a partir de una de las tres versiones de la Teoría de la Dependencia, en concreto, el enfoque de Fernando H. Cardoso y Enzo Faletto (1972, p. 24-25).

14 Desde cierta perspectiva, Kevin Gallagher (2016) considera que AL debería aprovechar las oportunidades que se presentan, combinando y aprovechando las relaciones tanto con EEUU como con China, mirando hacia ambos en una visión más amplia en la búsqueda de sus beneficios.

15 Casanova, Le y Ferreira (2015) cuantifican la exposición relativa de los países exportadores latinoamericanos ante cambios en la demanda china usando datos que fueron analizados para tres períodos de interés: el período 2003-2006, que marca los primeros años de crecimiento del comercio entre China y AL; el período 2007-2010, que incluye el inicio de la crisis financiera global y su respectiva recuperación; y, por último, el período 20112014, que refleja el comienzo de la caída de los precios de las materias primas en los mercados internacionales y el inicio de una era de menor crecimiento económico chino (ROLDÁN et al, 2016, p. 39). 
El mapa indica que Venezuela es el país latinoamericano más sensible a las fluctuaciones del comercio con China, seguido por Chile y Colombia, que también muestran una alta dependencia hacia este mercado asiático. La dependencia de Perú, Brasil y Argentina es menor, mientras que México, aunque es uno de los mayores exportadores latinoamericanos hacia China, no es tan dependiente, debido a la mayor diversificación de sus exportaciones y a la alta dependencia que sostiene con los EEUU. Otros países como Ecuador, Bolivia y Uruguay, pese a no estar entre los principales socios comerciales de China en esta región, tienen índices de dependencia bastante elevados (ROLDÁN et al, 2016, p. 39). Cabe destacar que la inversión china en productos básicos persiste, incluso después de la caída significativa en los precios de las materias primas, en 2014, cuando otras empresas extranjeras comenzaron a retomar inversiones más grandes en el sector extractivo de esta región.

Sin embargo, desde la perspectiva de la NEE, se comprende que el modelo de mercado chino, basado en el intercambio de lo que yo tengo, con lo que tú tienes, parte de un intercambio mutuo en igualdad de condiciones, trabajando juntos para alcanzar soluciones con múltiples ganancias (LIN; WANG, 2017, p. 4). China opera en una idea de "ayuda" con comercio, una perspectiva muy diferente a la que tiene el CAD, que identifica esta lógica como un "neocolonialismo" (importar recursos y exportar manufacturas). Visto de manera inversa, para China, la "ayuda” tradicional representa una limosna de carácter unilateral, aunque ese país no posea como tal una política de ayuda exterior, lo que deja al aire una posibilidad de definirla puntualmente, si bien tampoco imposibilita a que lo chinos tomen en cuenta la ayuda al exterior, plasmando los rubros en los que otorga ayuda en su libro Blanco.

Desde esta perspectiva, es inútil hacer una comparación entre la AOD y la lógica de la ayuda que otorga la RPCh. En este sentido, la lógica china va más allá incluso de los principios de la CSS, apoyándose más bien en el desarrollo de acciones donde China se presenta como un instructor de lo que sabe hacer bien, con lo que consigue una capacitación hacia el receptor, ayudándole a salir adelante con la propuesta en un enfoque de ganar-ganar. La propuesta china no es una receta acelerada como un salto al desarrollo ni mucho menos una propuesta a desafiar a las ventajas comparativas de cada país, más bien es un desarrollo gradual a través del fortalecimiento de esas ventajas comparativas, siempre y cuando estas se encuentran en el área de conocimiento de China, ya que no ofrece de ninguna manera enseñar lo que no sabe (LIN; WANG, 2017, p. 91-93). 
Ahora bien, en años más recientes, las exportaciones latinoamericanas hacia China han disminuido considerablemente en combustibles, productos mineros o metales, como en aquellos proveedores de alimentos o manufacturas. En general, se estima que la caída de dichas exportaciones fue del $14 \%$ en 2015, sumando tres años consecutivos de caída que afectaron a casi todos los países de la región (BID, 2015a ). Sin embargo, para el 2016 el volumen del comercio entre AL y China mostró un crecimiento del $1.3 \%$ y según las proyecciones, para el 2017 habría crecido hasta un $16 \%$, acercándose a los USD 266.000 millones, una cifra ligeramente inferior al máximo histórico de USD 268.000 millones alcanzado en 2013 (BID 2015b). Esto supone una importante recuperación después de tres años consecutivos de caídas del valor del intercambio bilateral, período en que se produjo una contracción acumulada del 14\%. La recuperación del valor de los envíos regionales a China, fue proyectada, en 2017, del $25 \%$, influida por los mayores precios del petróleo y otros productos básicos (CEPAL, 2018).

No obstante, en este escenario, las empresas chinas han volcado sus intereses hacia el sector de servicios, en línea con el cambio en la economía interna de China, donde los servicios están comprendiendo en más del 50\% de su Producto Interno Bruto (PIB). La mayor atención en los servicios, que van desde la generación y transmisión de electricidad hasta las tecnologías de la información, comunicaciones, finanzas y transportes, es un signo del aumento de la confianza cada vez mayor en estos productos por parte de consumidores de clase media latinoamericana. De este modo, en los últimos años la Inversión Extranjera Directa (IED) china hacia AL ha cambiado del sector agrario al sector servicio, tal y como se muestra en la siguiente gráfica. 
Grafica 2: IED China en América Latina, cambios al sector servicios

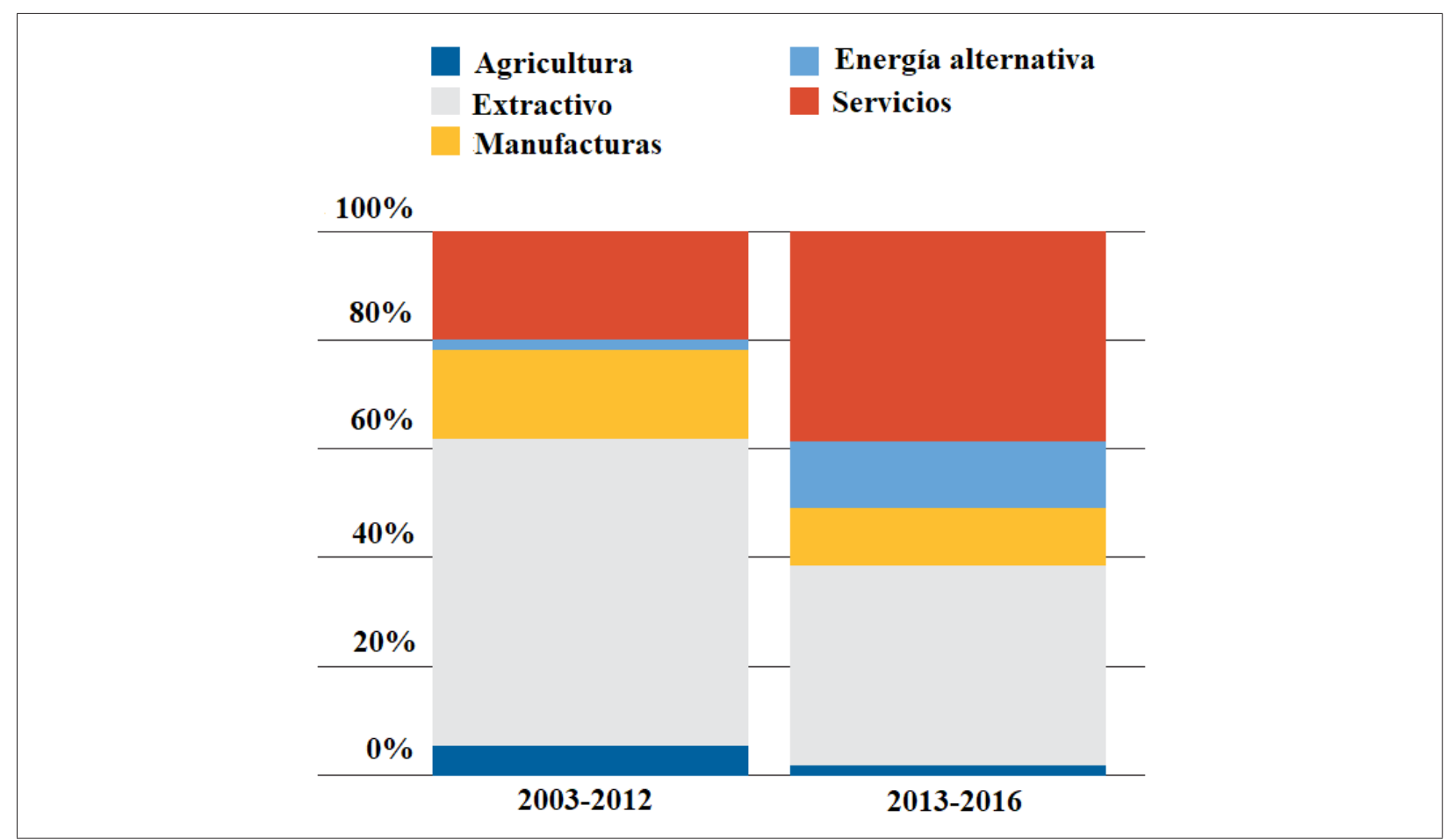

Fuente: Bureau van Dijk, FDI Markets, apud AVENDANO, MELGUIZO; MINER, 2017, p. 7.

Si bien las industrias extractivas siguen representando más del $60 \%$ de la IED total de China en la región, aunque del 2013 al 2016 ha disminuido en un $37 \%$ respecto al periodo comprendido entre 2003 a 2012. Por consiguiente, las inversiones en el sector de servicios han aumentado del $21 \%$ de la IED china de 2003 a 2012 a más del 50\% en los cuatro años siguientes (incluida la energía alternativa). La minería ha sido el sector más atractivo para el desarrollo de nuevos proyectos de inversión de China en AL, con un $27 \%$ del monto total de inversiones anunciadas entre 2004 y octubre de 2017. La diversificación sectorial de las inversiones chinas registrada permite observar que, mientras que los metales representaron el $42 \%$ y las energías fósiles el $18 \%$ del total de inversiones anunciadas entre 2004 y 2010, ambos sectores representaron solo el $20 \%$ y el $6 \%$ en el período más reciente 2011-2017. El cambio fue compensado por el aumento de las inversiones en sectores como los de telecomunicaciones, inmobiliario, alimentos o energías renovables, mostrando el interés de las empresas chinas por ingresar a nuevos sectores en la región. El sector de energía ha sido el principal objetivo de China en AL, pues el $49 \%$ del monto total de adquisiciones realizadas por empresas chinas en la región se volcó hacia este sector, con un $12 \%$ en energías renovables; la minería y las empresas de servicios básicos representaron el $9 \%$ y el $33 \%$ del total de las inversiones respectivamente. En este sentido, la venta de importantes empresas 
de energía en el Brasil explicaría un crecimiento sustantivo de las inversiones de China, cuyo valor alcanzó los USD 17,000 millones en 2017 (CEPAL, 2018, p. 57).

El nuevo enfoque de economía estructural considera que la IED representa una de las principales fuentes de beneficios económicos para los países receptores, ya que les permite crear fuentes de empleo, mejorar los salarios, recibir transferencia de conocimientos y tecnología, así como aumentar la productividad y el comercio en sus territorios. Eso es menos propenso a retrocesos repentinos durante los pánicos generados por los préstamos bancarios, el financiamiento de la deuda y la inversión de cartera, y no genera los mismos problemas de crisis financieras, como lo hacen los bruscos retrocesos de la deuda y los flujos de inversión de cartera (capital golondrino). Además, la IED generalmente trae tecnología, administración, acceso a mercados y redes sociales que a menudo faltan en los países en desarrollo y que son cruciales para la modernización industrial. Por lo tanto, la liberalización de la inversión directa debería ser, por lo general, un atractivo componente de una estrategia de desarrollo más amplia (LIN, 2012, p. 34). Los beneficios estratégicos para el país inversionista también son importantes, pues los efectos de la IED pueden ser sustanciales, incluyendo la percepción de una mejor imagen en el exterior, la persuasión a otros para que la acompañen en las organizaciones internacionales y la formación de políticas amistosas con otros países.

A diferencia de otros actores en la inversión internacional, las empresas chinas son prevalentemente estatales y han mostrado la capacidad de alinear las tendencias económicas con las prioridades de su gobierno, haciendo explícito su principio de respeto mutuo y no interferencia en los asuntos internos de los países. Es relevante destacar que los flujos acumulativos de IED china en AL han alcanzado más de USD 110.000 millones, de los cuales USD 60.000 millones se concentraron solo en Brasil (AVENDANO; MELGUIZO; MINER, 2017, p. 2-6).

China está en condiciones de situarse, a partir de la Nueva Ruta de la Seda, como el nuevo líder de un régimen internacional de CSS y, en este sentido, es importante señalar que esta iniciativa abarca también (por la Ruta Marítima) a AL con algunos de los macro proyectos financiados con capital chino, como la plataforma de la isla de Cuba, a modo de base naval, y los proyectos de comunicación del Gran Canal de Nicaragua, el ferrocarril bioceánico Brasil-Perú y el túnel Argentina-Chile (DOMÍNGUEZ, 2018, p. 56).

Por ello, no es de extrañarse que la IED procedente de China haya aumentado notablemente en la región, pues desde 1990 llegaron a la región cerca de USD 7.000 millones de inversión directa china, cifra que se duplicó tan solo en el año 2010, 
acercándose a los USD 14.000 millones (equivalentes a un 11\% de la IED total recibida por la región en ese año) ${ }^{16}$. Aunque después de 2010 se registró menor intensidad en las inversiones chinas, que fueron entre USD 6.000 y USD 10.000 millones anuales, siguieron representando entre un $3 \%$ y un $8 \%$ de los flujos totales de IED recibidos por AL (CEPAL, 2016, p. 40). En total, entre 2005 y 2016, ingresaron a la región cerca de USD 90.000 millones procedentes de China, cifra que representa aproximadamente el $5 \%$ de la IED recibida por AL (CEPAL, 2018, p. 56).

Si bien es cierto que entre 2010 y 2014 cerca del $90 \%$ de las inversiones chinas estimadas se dirigieron hacia recursos naturales, dicho sector absorbió solo el $25 \%$ del total de este tipo de inversiones que la región recibió desde otras partes del mundo en el mismo período. Pese a que los anuncios de nuevos proyectos de inversión chinos en la región cayeron de USD 10.000 millones en 2014 a USD 3.700 millones en 2015, China se posicionó como el quinto país con mayores montos de inversión anunciados en AL, después de los EEUU, España, Francia y Japón. Entre 2005 y 2015, la mitad de esta inversión anunciada correspondió a proyectos en Brasil (30\%) y Perú (20\%), se sobresaliendo, también, México (13\%), Argentina (9\%) y Venezuela (5\%). Las inversiones efectivamente materializadas en México aún se mantienen en niveles muy bajos, representando apenas el 0,1\% del total de la IED recibida por este país en 2015, ya que para finales de 2014 se cancelaron dos grandes proyectos: el Dragon Mart, en Cancún, y el tren de alta velocidad entre la Ciudad de México y Querétaro (CEPAL, 2016, p. 47). Para el 2017, se produjo un aumento marcado de los montos totales de IED china en AL, alcanzando un estimado de USD 25.000 millones, lo que representa el 15\% de lo ingresado a esta región en ese año. Desde 2005 a 2017, Brasil es el país latinoamericano que ha recibido más IED procedente de China, concentrando el $55 \%$ del total de esta inversión, seguido por Perú con el 17\% y la Argentina con el 9\%. Juntos estos tres países concentran el $81 \%$ de los ingresos de IED de China en la región (CEPAL, 2018, p 56).

Por último, otro de los aspectos fundamentales de la NEE es el otorgamiento de préstamos no-concesiónales, en los que China ha jugado un papel relevante como nueva fuente de financiamiento a sus socios. A diferencia de los préstamos del Fondo Monetario Internacional (FMI) y del Banco Mundial (BM), los chinos no

16 En 2010, tres cuartas partes del total de la IED china en la región correspondieron prácticamente a dos grandes adquisiciones en la industria petrolera, efectuadas por Sinopec en el Brasil y por CNOOC en la Argentina, aunque también otras empresas chinas de diferentes sectores llegaron a la región o aumentaron considerablemente su presencia en ese mismo año (CEPAL, 2016). 
imponen condiciones políticas a cambio de ayuda e inversión, lo cual ha erosionado profundamente algunos de los fundamentos del Consenso de Washington (VADELL; RAMOS; NEVES, 2014, p. 96). En general, los préstamos chinos en AL han sido complementarios en términos de cobertura de países en comparación con el financiamiento multilateral de las fuentes de financiamiento tradicional.

El núcleo del financiamiento chino en esta región se ha concentrado principalmente en infraestructura, energía y minería, en contraste con las instituciones financieras internacionales, incluyendo la Confederación Andina de Fomento (el Banco de Desarrollo de AL) (CAF), el Banco Interamericano de Desarrollo (BID) y el BM, que se han enfocado más en mercados financieros, educación, salud, medio ambiente y en algunos aspectos de la administración pública como la modernización del Estado y la impartición de justicia. Como se observa en la siguiente gráfica, entre 2007 y 2014, AL recibió más dinero de China que del BM y del BID juntos, pues los bancos chinos tienen la posibilidad de financiar a empresas o países a los que las entidades tradicionales no pueden acceder, estableciendo acuerdos basados en un intercambio de servicios y productos, y no solo de dinero, de esta forma los chinos exigen bajos intereses, actuando en zonas más pobres o con economías más volubles (CASAS, 2015).

\section{Grafica 3. Préstamos bilaterales y multilaterales seleccionados en América Latina} (en millones de dólares)

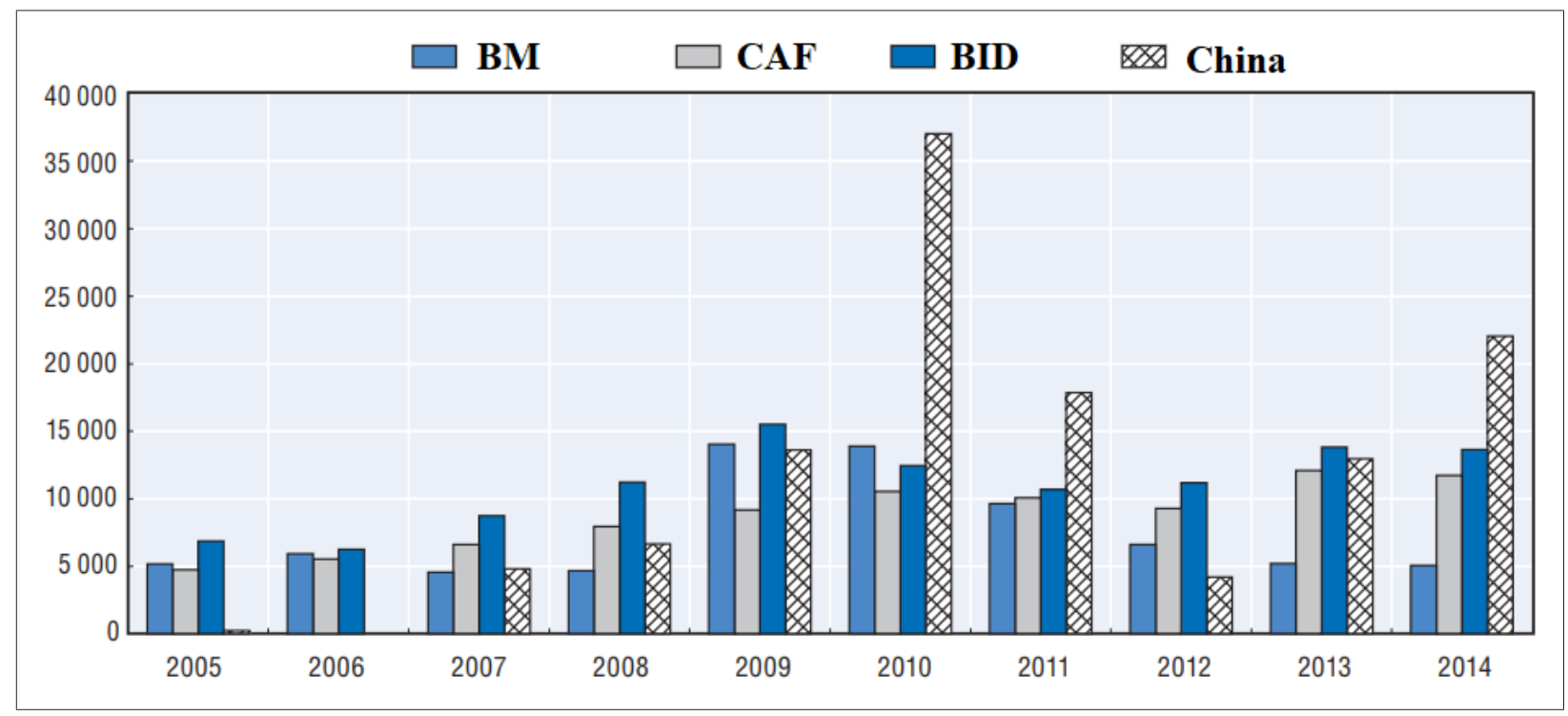

Fuente: OECD; ECLAC; CAF, 2015. p. 15217

17 Los préstamos chinos incluyen aquellos proporcionados, principalmente, por el China Development Bank y China ExIm Bank. Los préstamos del Banco Mundial son del Banco Interamericano de Reconstrucción y Fomento y Compromisos de Asociación Internacional de Fomento (GALLAGHER; MYERS, 2017). 
En 2010, por ejemplo, la RPCh prestó USD 10.000 millones a Argentina con bajo interés, para que este país sudamericano construyera una red ferroviaria. Las empresas encargadas del proyecto eran socias del Estado chino, por lo que el receptor último del dinero era la propia China. Este tipo de garantías son las que permiten a China fijar condiciones tan competitivas, pues, cerca del $69 \%$ de los préstamos emitidos por este país asiático en AL se han hecho a cambio de petróleo que respalda la deuda y mantiene el riesgo a un nivel mínimo. Además, el dinero chino es más atractivo que el de los oferentes tradicionales, porque no impone medidas intervencionistas, es decir, Beijing no controla la transparencia ni la eficiencia de la inversión, mientras que organismos como el BM exigen declaraciones financieras o informes de evaluación a los prestatarios. Por eso, muchos de los países con gobiernos de izquierda han preferido recurrir a China para evitar, así, la imposición de políticas neoliberales (CASAS, 2015).

Entre 2005 y 2017, el financiamiento multilateral y bilateral chino se dirigió principalmente a Venezuela, con un total de 17 préstamos por valor de USD 62.200 millones, seguido por Brasil, que recibió 12 préstamos por USD 42.100 millones, continuando Argentina con 11 préstamos por valor de USD 18.200 millones, Ecuador con 13 préstamos por USD 17.400 millones y Bolivia, que recibió 10 préstamos por USD 3.500 millones. Sin embargo, como se muestra en la gráfica que sigue, en 2017, el financiamiento chino en AL llegó a su nivel más bajo de los últimos cinco años, con tan solo USD 9.000 millones, debido a que dos bancos estatales chinos - China Development Bank y Eximbank - se abstuvieron de realizar préstamos a Venezuela ${ }^{18}$.

Grafica 4. Financiamiento Estatal de China en América Latina (2007-2017) (en millones de dólares)

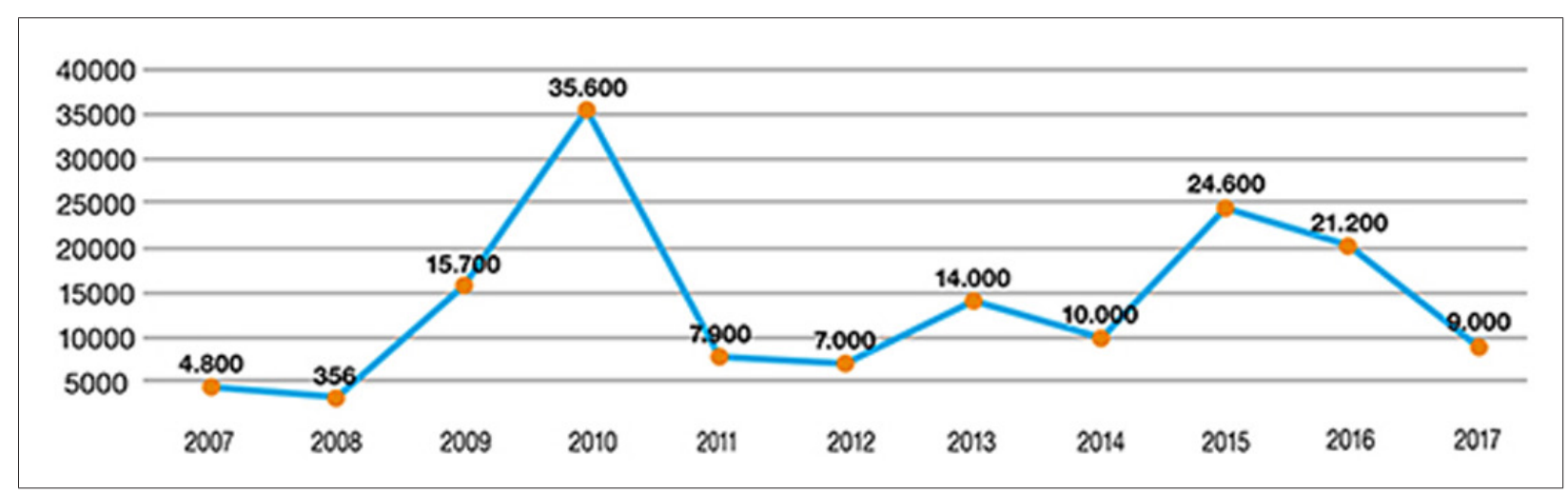

Fuente: GALLAGHER \& MYERS (2017).

18 Aunque China continúa comprometida diplomáticamente, los funcionarios chinos se han vuelto cada vez más cautelosos con las condiciones de los préstamos a Venezuela (MYERS; GALLAGHER, 2018). 
La disminución en el financiamiento de China en AL también se debe a que otras fuentes de financiamiento, como los fondos regionales, han adquirido mayor relevancia en los últimos años, pero podría volver a aumentar si se aprueban proyectos integrados a la iniciativa china la Nueva Ruta de la Seda en esta región (MYERS; GALLAGHER, 2018). No obstante, como se ha expuesto en este apartado, el fortalecimiento del comercio y la inversión de infraestructuras en transportes, telecomunicaciones y energéticos como ejes sobre los que se debe mover la ayuda, ha fraguado una relación más estrecha entre China y AL en sectores públicos y privados, que ha ido desdibujando las líneas marcadas por la cooperación y la ayuda tradicionales, avanzando así en la senda que propone la NEE.

\section{Consideraciones Finales}

¿Estamos frente a una NEE en AL? y ¿en qué se diferencia la cooperación china con respecto al sistema tradicional de ayuda? Para responder a estas preguntas, hemos apuntado en este trabajo que, en primer lugar, la NEE se encuentra en un momento inicial y AL podría asumir un papel importante en los próximos años si consideramos las enormes relaciones políticas, económicas, comerciales y de ayuda que se han construido a lo largo de estos últimos casi 20 años. Aunque a lo largo de este trabajo se ha intentado señalar esta estrategia en la región, es también cierto que AL vive al igual que las demás regiones del mundo un fenómeno de fuerte acercamiento al gigante asiático que va asumiendo año tras año dimensiones cada vez más grandes. En segundo lugar, es importante señalar como la cooperación china sustentada en la NEE abriría un parteaguas importante con respecto a la forma en que se han dado los flujos de cooperación tradicional, recuperando por un lado aquella visión altruista de la CSS de la segunda posguerra del siglo pasado, y, por otro lado, abriendo la misma concepción en que se ha entendido la ayuda hasta nuestros días. En ese sentido, y aunado a ello, es posible observar como el CAD, a través de los Total Official Support for Sustenaible Development (TOSSD), ha creado un nuevo mecanismo de ayuda que se presenta como alternativo tanto a la visión tradicional de la AOD como a la misma manera en que la RPCh ha entendido su forma de cooperar y ayudar. Abriendo al capital privado la AOD y direccionando todo este esfuerzo hacia el conseguimiento de los Objetivos del Desarrollo Sostenible (ODS), se está desdibujando un nuevo modelo de cooperación en competencia con el modelo chino que no se rige por los patrones de la AOD y del CAD. Esto ha generado un nuevo modelo de colaboración que 
entremezcla comercio, inversiones, préstamos y créditos, permitiendo a los países con dificultades acceder a los mercados internacionales con dichos financiamientos (DREHER; FUCHS, 2012, p. 4).

El interés de China es incorporar tecnologías y conocimientos en sus exportaciones, para generar transformaciones estructurales en sectores de alta productividad en AL, pues, desde 2015, los chinos se han consolidado como los mayores productores mundiales de manufacturas, los mayores exportadores y los segundos importadores de bienes, mostrando un creciente interés en el sector servicios, absorbiendo cerca de una cuarta parte de la producción mundial de bienes manufactureros (CEPAL, 2016, p. 9).

Con ello, los países latinoamericanos también reforzaron su acervo de inversiones recíprocas con el país asiático, contemplando una cifra de al menos USD 250.000 millones para el 2025, poniendo de manifiesto que las inversiones chinas en esta región, lejos de disminuir, pretenden aumentar y diversificarse en actividades no extractivas que contribuyan a la creación de capacidades productivas y empleos de calidad en los países receptores. Las perspectivas de un crecimiento en AL y la inversión china en esta región pueden jugar un papel importante en la continuación de la trayectoria ascendente, avanzando hacia una NEE.

Aunque AL todavía carece de una estrategia consolidada hacia el gigante asiático, mostrando su necesidad de priorizar en temas como la tecnología, la creación de cadenas de valor, la ampliación de la oferta exportadora y la generación de mayor productividad avanzan con fuerza en la senda de la NEE a través de encadenamientos productivos cada vez más sólidos con China, impulsando sus ventajas comparativas en el nuevo orden internacional que sigue gestándose.

Finalmente, podríamos decir que esta nueva identidad de la cooperación china sigue en construcción, poniendo en evidencia que se rehace en los intereses de la CSS del siglo pasado, pero que hoy, en una realidad totalmente diferente, recuperar sus principios significa no solamente sentar las bases para un nuevo modelo de cooperación sustentado en la Nueva Economía Estructural, sino también apunta hacia la construcción de un nuevo orden multipolar basado en la paz, en la cooperación internacional, más que en la hegemonía, la extrema inequidad y la guerra (HARRIS, 2016, p. 512). Claramente, este trabajo ha intentado mostrar cuales son los pilares de esta nueva identidad de la cooperación china, sin embargo, este análisis abriría el debate también hacia los beneficios y/o dependencia que esta relación podría causar. En este sentido, futuras investigaciones alrededor de esta temática deberán considerar estos otros elementos para avanzar en el entendimiento de este nuevo orden multipolar al que apunta China. 


\section{Referencias}

AVENDANO, Rolando; MELGUIZO; Angel; MINER, Sean. Chinese FDI in Latin America, New Trends with Global Implications. OECD Development Centre, 2017.

BID. BANCO INTERAMERICANO DE DESARROLLO La caída del 14\% de las exportaciones regionales acentúa la importancia de promover la diversificación comercial. 14 dic. 2015a. Disponible en: < http://www.iadb.org/es/noticias/comunicados-deprensa/2015-12-14/exportaciones-latinoamericanas-caen-14,11365.html > . Acceso en: 20 de junio de 2017.

. Aumentan las exportaciones de América Latina y el Caribe por primera vez en cuatro años. 14 dic. 2015b. Disponible en: < http://www.iadb.org/es/noticias/ comunicados-de-prensa/2015-12 14/exportaciones-latinoamericanas-caen-14,11365. html > . Acceso en: 20 de junio de 2017.

BBC. Los grandes intereses de Taiwan en Centroamérica, a pesar de la poderosa influencia China. 11 ene 2017. Disponible en: < http://www.bbc.com/mundo/noticiasinternacional-38578955 > . Acceso en: 20 de junio de 2017.

CASAS, Alba. Los préstamos de China en América Latina crecieron 22,000 millones. 02 feb. 2015. Disponible en: < http://elpais.com/economia/2015/02/27/actualidad/ 1425072766_388301.html >. Accesado en: 20 de septiembre de 2017.

CEPAL. COMISIÓN ECONÓMICA PARA AMÉRICA LATINA Y EL CARIBE People’s Republic of China and Latin America and the Caribbean. Ushering in a new era in the economic and trade relationship. Santiago de Chile. Naciones Unidas. 2011.

. Relaciones económicas entre América Latina y el Caribe y China, oportunidades y desafíos. Santiago de Chile. Naciones Unidas, 2016.

- Explorando nuevos espacios de cooperación entre América Latina y el Caribe y China. Santiago de Chile. Naciones Unidas, 2018.

CARDOSO, Fernando Henrique; FALETTO, Enzo. Dependencia y desarrollo en América Latina. México: Siglo XXI, 1972.

DREHER, Axel; FUCHS, Andreas. Rogue aid? The determinants of China's aid allocation. Discussion Papers Courrant Research Center, n. 93, 2012, p. 1-48.

DOMÍNGUEZ, Rafael. La crisis de identidad del sistema de ayuda. Nombres Propios Fundación Carolina, p. 1-6. 2011.

DOMÍNGUEZ, Rafael. Cooperación Financiera para el desarrollo, ADN de la Cooperación Sur-Sur. Monográfico de Cooperación. Revista Iberoamericana de Estudios de Desarrollo, n. 6, p. 62-86, 2016.

. En los pliegues de la historia: Cooperación Sur-Sur y procesos de integración en América Latina y el Caribe. Estudos internacionais, v. 4 n. 2, p. 57-78. 2017. China y la construcción de un régimen internacional de Cooperación Sur-Sur. Carta Internacional, v. 13, n. 1, p. 38-72. 2018. 
DOMÍNGUEZ, Rafael; RODRÍGUEZ, Gustavo (eds.). Historia de la Cooperación Internacional desde una perspectiva crítica, Cartagena de Indias: RIACI-UAC. 2017.

GALLAGHER, Kevin. The China triangle: Latin America's China boom and the fate of the Washington consensus. Oxford University Press. 2016.

GALLAGHER, Kevin P.; MYERS, Margaret. China-Latin America Finance Database. Washington: Inter-American Dialogue. 2017.

HARRIS, Richard, L. China's South-South Cooperation with Latin American and the Caribbean. Journal of Developing Society, no. 32, vol. 4, p. 508-556, 2016.

HONGBO, Sun. China's Aid to Latin America and the Caribbean Region. En H. Zhou (ed.). Chinas Foreign Aid, 60 Years in Retrospect, p. 281-324. Social Sciences Academic Press \& Springer, Singapore. 2017.

IISCAL. INICIATIVA PARA LAS INVERSIONES SUSTENTABLES CHINA-AMÉRICA LATINA. La visita del Presidente Xi Jinping a Ecuador Perú y Chile. 12 sep. 2016. Disponible en: < http://www.bankinformationcenter.org/wp-content/uploads/2016/12/9-BoletinIISCAL-v11.pdf > . Acceso en: 20 de octubre de 2017 .

LEMUS, Daniel Ricardo. Regímenes de verdad: el Comité de Ayuda al Desarrollo y la narrativa histórica de la cooperación internacional para el desarrollo. En DOMÍNGUEZ, Rafael \& RODRÍGUEZ, Gustavo (eds.). Historia de la Cooperación Internacional desde una perspectiva crítica, Cartagena de Indias: RIACI-UAC. 2017.

LIN, Justin Yifu. Nueva Economía Estructural, un marco para reformular el desarrollo. Documento de trabajo sobre investigación de políticas 5197, p. 1-39, Banco Mundial. 2010.

LIN, Justin Yifu. New Structural Economics, A Framework for Rethinking Development and Policy. Washington D.C. World Bank, 2012.

LIN, Justin Yifu; WANG, Yan. Going Beyond Aid, Development, Cooperation for Structural Transformation, United Kingdom: Cambridge Press University. 2017.

LO BRUTTO, Giuseppe; GONZÁLEZ, Cruz Humberto. La influencia China en la Cooperación Sur-Sur Latinoamericana, durante la segunda década del Siglo XXI. Catedra COIBA DT cooperación y desarrollo, 2015/02. p. 1-15. 2015.

LO BRUTTO, Giuseppe. A propósito de la cooperación internacional y del desarrollo. En DOMÍNGUEZ, Rafael; RODRÍGUEZ, Gustavo (eds.). Historia de la Cooperación Internacional desde una perspectiva crítica, Cartagena de Indias: RIACI-UAC. 2017. MARTÍNEZ Gustavo. Los TLC latinoamericanos con China. 22 ene. 2015. Disponible en < http://www.chinatoday.mx/eco/clae/content/2015-01/22/content_664856.htm. Acceso en: 15 junio de 2017.

MRERPC. MINISTERIO DE RELACIONES EXTERIORES DE LA REPÚBLICA POPULAR CHINA. Documento sobre la Política de China Hacia América Latina y el Caribe. 24 nov. 2016. Disponible en: < http://www.fmprc.gov.cn/esp/zxxx/t1418256.shtml > . Acceso en: 20 de octubre de 2017. 
MYERS, Margaret; GALLAGHER, Kevin P. Chinese development finance "down but not out" in Latin America. 30 mar. 2018. Disponible en: < http://theglobalamericans.org/ 2018/03/chinese-development-finance-not-latin-america/ > . Acceso en: 20 de octubre de 2018.

OECD; ECLAC; CAF. ORGANISATION FOR ECONOMIC CO-OPERATION AND DEVELOPMENT; ECONOMIC COMMISSION FOR LATIN AMERICA AND THE CARIBBEAN; CORPORACIÓN ANDINA DE FOMENTO. Latin American Economic Outlook 2016: Towards a New Partnership with China, OECD Publishing, Paris. 2016. OECD. ORGANISATION FOR ECONOMIC CO-OPERATION AND DEVELOPMENT. Es AOD? nov. 2008. Disponible en: < http://www.oecd.org/dac/stats/Es \% 20AOD \% 20 Nov\%202008.pdf > . Acceso en: 27 de julio de 2017.

PORTELLES, Yurien. China apuesta a alianza estratégica " $1+3+6$ " con Celac. 7 ene. 2015. Disponible en: //www.andes.info.ec/es/noticias/china-apuesta-alianza-estrategica136-celac.html. Acceso en: 20 de octubre de 2017.

ROLDÁN, Adriana.; CASTRO, Alma Sofía.; PÉREZ, Camilo Alberto.; ECHAVARRÍA, Pablo. \& EVAN, Roberto. La presencia China en América Latina, comercio inversión y cooperación económica. Colombia: Fundación Konrad Adenauer. 2016.

SANTANDER, Guillermo. Identidades e intereses en la cooperación sur-sur, los casos de Chile, Venezuela y Brasil. Madrid: Catarata. 2016.

UNSD. UNITED NATIONS STATISTICS DIVISION. United Nations Commodity Trade Statistics Database. 2017. Disponible en: < http://comtrade.un.org > . Acceso en: 22 de septiembre de 2017.

VADELL, Javier; RAMOS, Leonardo; NEVES, Pedro. The international implications of the Chinese model of development in the Global South: Asian Consensus as a network power. Revista Brasileira de Política Internacional, no. spe. vol. 57, p. 91-107. 2014. 